\title{
Behavioural response of the woodwasp Sirex noctilio to volatile emissions of its fungal symbiont
}

\author{
A. A. Fernández Ajó*, A. S. Martínez *, J. M. Villacide \& J. C. Corley \\ Grupo de Ecología de Poblaciones de Insectos, EEA INTA Bariloche, Río Negro, Argentina
}

\section{Keywords}

Amylostereum areolatum, host finding behaviour, Hymenoptera, integrated pest management, semiochemical, synomone, wood-boring insect

\section{Correspondence}

Andrés S. Martínez (corresponding author), Grupo de Ecología de Poblaciones de Insectos, EEA INTA Bariloche, Modesta Victoria 4450, (8400) Bariloche, Río Negro, Argentina.

E-mail: andmarv77@gmail.com

Received: November 10, 2014; accepted: January 6, 2015

doi: $10.1111 /$ jen.12211

*These authors contributed equally to the work.

\begin{abstract}
The wood-boring wasp, Sirex noctilio, is a global invasive pest that infects and kills pine trees by inoculating spores of a symbiotic fungus (Amylostereum areolatum) at oviposition. Wasp larvae depend on fungal growth to feed, while the fungus relies on female wasps to initially condition the pine tree by inoculating a phytotoxic venom and for dispersal. Wasp larvae use the fungus as an external gut for the digestion of lignocellulosic compounds resulting in a strong correlation between fungal growth inside the wood and wasp fitness. This study explores the hypothesis that female wasps will use fungal volatiles as a synomone in the process of locating suitable oviposition areas (i.e. trees). Using a Y-tube olfactometer, adult female wasp behaviour was assessed towards fungal and pine tree volatiles (i.e. positive control). Our results are the first to demonstrate attraction of female $S$. noctilio towards volatiles of their fungal symbiont. Furthermore, the positive response towards these volatiles seems to be stronger than the response to a known attractant (i.e. pine volatiles). These results could be an important contribution to improving baits for monitoring and control purposes. Further work is needed, mainly oriented towards the identification of the volatiles that trigger the observed attraction response and their possible synergistic effects with tree volatiles.
\end{abstract}

\section{Introduction}

The European woodwasp, Sirex noctilio Fabricius (Hymenoptera: Siricidae), is an invasive pest of pines worldwide. The wasp attacks a variety of pine species and is the only member of the siricid family capable of killing healthy trees (Spradbery 1973; Bordeaux and Dean 2012). Sirex noctilio is native to Eurasia and North Africa but over the last century, economic losses have been caused by accidental introductions into regions where pines are cultivated in the southern hemisphere. More recently, the wasp established in North America (Slippers et al. 2011) where it has the potential to impact native pine forests.

Female wasps introduce a phytotoxic mucus and spores of the fungal symbiont Amylostereum areolatum Boidin (Basidiomycotina: Corticiaceae) into the wood. It has been suggested that the mucus promotes fungal establishment, while $A$. areolatum mycelia is essential for wasp development since it is believed that larvae cannot directly ingest wood, but depend on the symbiont for processing lignocellulosic compounds (Thompson et al. 2014). Due to the combined effects of the phytotoxic mucus and the fungus, trees that suffer strong attacks often die (Spradbery 1973; Bordeaux and Dean 2012).

It is important to note that wasp adults do not feed; hence, nutrients that will be allocated to somatic maintenance and locomotion are derived entirely from resources acquired during the larval stages (Taylor 1981). This results in wasp fitness being strongly linked to the location of adequate oviposition substrates that will favour fungal growth. Favourable fungal growth conditions, found in trees with appropriate wood moisture levels and aeration, may promote larger female wasps that will live longer, carry more eggs (Madden and Coutts 1979) and perform longer sustained flights (Bruzzone et al. 2009), 
facilitating the geographical spread of both wasp and fungus.

Previous studies have established that wasp females are attracted to stressed trees and use volatile emissions (primarily monoterpenes) to find them (Simpson 1976; Simpson and Mcquilkin 1976). Defences of stressed trees are easier to overcome than those of healthy ones, which is why such trees are favoured oviposition sites for female wasps (Bordeaux and Dean 2012). Many of the volatile compounds produced by stressed pines, have been shown to elicit behavioural and antennal response in the wasp (Simpson 1976; Simpson and Mcquilkin 1976; Madden 1988; Böröczky et al. 2012) and some of them (i.e. $\alpha$ and $\beta$ pinenes in a ratio of $70: 30$, respectively) are used to sample and monitor female wasp populations in affected areas (Bashford 2008; Martínez et al. 2014). Regardless of these findings, to date the most commonly used way to monitor wasp populations when in low densities is the use of girdled or herbicide-treated pines as a lure, which are costly and logistically difficult to implement (Zylstra et al. 2010).

While some studies on the chemical ecology of the woodwasp have focused mainly on the volatiles produced by host pine species, more recently Cooperband et al. (2012) identified a male produced pheromone which is active both on females and males in laboratory assays but not in the field (Hurley et al. 2014). However, knowledge on the role played by symbiont Amylostereum areolatum volatiles on wasp behaviour remains an open question. In this study, we hypothesize that fungal volatiles could be used as synomones indicating the location of previously attacked trees to female wasps. The summed effect of numerous female ovipositions in a tree could facilitate overcoming tree defences as more phytotoxic mucus and fungal spores are inoculated into the wood (Coutts 1969a,b; Thompson et al. 2014). Such behaviours could also lead to observed spatial aggregation and faster growing populations (Corley et al. 2007; Aparicio et al. 2013). We conducted laboratory experiments to evaluate the behaviour of $S$. noctilio females towards fungal volatiles that could be used in the process of locating previously attacked trees.

\section{Methods and Materials}

\section{Sirex noctilio rearing}

Female adults used in all experiments were obtained from trees felled in attacked plantations near the city of Bariloche, Argentina. Pine trees (Pinus contorta var. latifolia Engelm.) were all naturally attacked by $S$. noc- tilio and selected by looking for the typical oviposition symptoms (i.e. resin beads at each ovipositor insertion). After felling, trees were cut to 1-m-long billets and kept at $22 \pm 3{ }^{\circ} \mathrm{C}$ in locker-type cages with natural lighting in the rearing facilities at INTA EEA Bariloche until wasps emerged. Insects were collected daily and placed in individual containers for at least 50 min before bioassays. Females used in bioassays were 1-4 days old with an average thorax width of $393 \pm 117 \mathrm{~mm}$.

\section{Fungal culture}

Amylostereum areolatum volatiles used in choice tests were obtained from artificial cultures. Hyphal fragments were extracted from Sirex noctilio female mycangia and grown in Petri dishes on a medium based on agar-agar, malt, yeast and pine extract (Martínez et al. 2006). The fungus was left to grow in an incubator at $25 \pm 1{ }^{\circ} \mathrm{C}$ and $70 \pm 5 \% \mathrm{RH}$ until the full surface of the Petri dish was covered by the mycelium (18 \pm 3 days). The mycelium was used as volatile production substrate during bioassays by removing a circular portion $\left(7.9\right.$ or $23.6 \mathrm{~cm}^{2}$ ) using a sterile glass puncher. Petri dishes with sterile culture medium were left in the incubator during the same period to be used as controls during the experiments.

\section{Bioassays}

All trials were conducted under controlled temperature $\left(25 \pm 1{ }^{\circ} \mathrm{C}\right)$ and artificial light conditions (700 Lm) between November 2013 and April 2014. We used a custom-made glass Y-tube olfactometer (base $35 \mathrm{~cm}$, arms $19 \mathrm{~cm}$, diameter $4 \mathrm{~cm}$ ), connected to an air pump creating an air flow of $0.1 \pm 0.02 \mathrm{l} / \mathrm{min}$. Air entering the olfactometer arms was previously filtered through $200 \mathrm{~g}$ of activated charcoal and then humidified through $0.25 \mathrm{l}$ of distilled water. Two odour sources were placed inside individual sealed glass containers and attached via silicone tubing (inner diameter $6.6 \mathrm{~mm}$ ) to each of the olfactometer arms. Volatile sources/control treatments, were introduced in the containers and replaced every five replicates (i.e.: 1 replicate $=1$ wasp). To reduce visual stimuli/asymmetries during the bioassay, the olfactometer was placed inside a black corrugated plastic box. Wasp behaviour was observed using a webcam (Logitech HD, C310) connected to a laptop. After each replicate, females were discarded. All glassware was thoroughly cleaned with non-ionic soap (Novanil-Novara S.R.L., Argentina) and rinsed with distilled water after every replicate. To account for irregularities in the olfactom- 
eter arms that could bias wasp behaviour, the odour sources were interchanged after each replicate.

\section{Experimental procedure}

Wasps were introduced into the base of the olfactometer and left to acclimatize during 2 min during this period, and wasps were restricted to walk upwind by means of a pivoting metal gate (mesh $2 \mathrm{~mm}$ ) which was then opened utilizing a magnet from the outside, once the acclimation period was over. A choice was considered as such when within the first $7 \mathrm{~min}$ of starting the assay (acclimation time was not considered), the female entered at least $13 \mathrm{~cm}$ into one of the arms and remained there for $10 \mathrm{~s}$. Wasps that did not enter an arm of the olfactometer after $7 \mathrm{~min}$ had elapsed were considered non-responders. A minimum of 19 responding wasps were used per experiment. The following parameters were recorded for each responding wasp; the arm/odour source chosen and the time taken to make the choice. For each experiment, the overall response level was calculated (number of responding wasps/total wasps tested (responders + non-responders) $\times 100$ ); the percentage of wasps responding to each of the treatments and the average time taken to respond were calculated.

\section{Experiments}

Four separate experiments were carried out. The response of adult Sirex noctilio females was assessed towards clean air, a known attractant and two different concentrations of volatiles derived from artificial cultures of $A$. areolatum. The first two experiments were carried out to provide baseline information about wasp behaviour in the olfactometer: (i) the response towards clean air in both arms was evaluated, expecting to observe no statistical differences in the choices and (ii) the response towards volatiles known to attract females $S$. noctilio in the field $(20 \mu \mathrm{l}$ of a $70: 30 \alpha$ pinene $((-)-\alpha$-Pinene $99 \%$ Aldrich Inc. UK - P45702) and $\beta$ pinene $((-)-\beta$-Pinene 99\%, Aldrich Inc. UK - 112089), on a $1 \times 1 \mathrm{~cm}$ filter paper) vs. clean air $(1 \times 1 \mathrm{~cm}$ clean filter paper $)$. The last two experiments consisted of fungal volatiles presented in two different concentrations: (i) a low concentration of fungal volatiles (a $7.9 \mathrm{~cm}^{2}$ circular portion of mycelium) vs. the same surface of sterile culture medium and (ii) a higher concentration (a $23.6 \mathrm{~cm}^{2}$ circular portion of mycelium) vs. the same surface of sterile culture. Sterile medium was used as olfactory control and to balance any humidity differ- ences between both arms (Martínez and Hardie 2009).

\section{Statistical analysis}

Data were analysed at three different scales. The first analysis took into consideration the differences in overall response levels (wasps that responded to any of the arms vs. ones that did not respond at all) while a second level of analysis took into account the response percentage of responding wasps. In both cases, Pearson's Chi-Squared Tests were used. Differences across experiments were analysed by multiple comparisons performed via Tukey tests with a generalized linear model using a binomial error structure (GLM function with logit link function). In a third stage, we compared the time taken by female wasps that responded towards a target stimulus (either pinenes or fungi in low or high concentration) with the nonparametric Wilcoxon Test for multiple comparisons. All comparisons were done using the $\mathrm{R}$ statistical environment ( $\mathrm{R}$ Development Core Team 2011).

\section{Results}

Statistical differences were found in the overall response levels between the four experiments $\left(\chi^{2}=17.4 ; \mathrm{P}=0.0006 ;\right.$ d.f. $=3$, fig. 1 $)$. Response was lowest when individuals were subjected to clean air; only $36 \%$ of females tested responded within the pre-established 7 min to any of the arms of the olfactometer. When females were exposed to pinenes vs. clean air, the proportion of responding wasps was $52 \%$. Finally, when female response was tested towards the fungal volatiles (at either dose), the number of responding wasps increased to ca. $70 \%$. Pair-

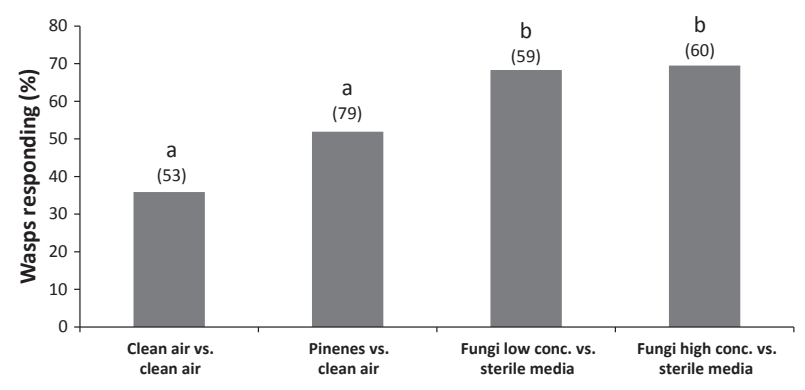

Fig. 1 Percentage of Sirex noctilio responding towards the stimuli of the olfactometer (response) vs. females that did not respond to any of the arms (no response). Four separate experiments were done using different combinations of odour stimuli. Numbers in parentheses indicate the total individuals tested in each experiment. Different letters on top of the bars indicate statistical differences between experiments $(P<0.05)$. 
wise comparisons between experiments showed that clean air and pinene experiments had the lowest response levels, while responses towards both experiments containing fungi had the highest overall responses (control vs. high fungus: $Z=3.5$; $\mathrm{P}=0.002$; $\quad$ control vs. low fungus $Z=3.4$; $\mathrm{P}=0.004$; control vs. pinenes: $Z=1.8 ; \mathrm{P}=0.27$; low fungus vs. high fungus: $Z=0.1$; $\mathrm{P}=1.0$; pinenes vs. high fungus: $Z=2.0 ; \mathrm{P}=0.16$; pinenes vs. low fungus: $Z=1.9 ; \mathrm{P}=0.2$ ).

Comparisons between choices made by responding wasps within each experiment showed that wasps were not biased towards any of the olfactometer arms when clean air was presented in the arms $\left(\chi^{2}=0.47\right.$; $\mathrm{P}=0.49$; d.f. $=1$; fig. 2 ). The response of females exposed to clean air and pinenes resulted in a significantly larger percentage of females choosing the arm that contained the known attractant $\left(\chi^{2}=4,1\right.$; $\mathrm{P}=0,04$; d.f. $=1)$. When tested against the artificial fungal culture, significantly more females chose the arm containing fungal volatiles (regardless of their concentration) compared with the arm with the sterile medium (low concentration experiment: $\chi^{2}=7.0$; $\mathrm{P}=0.008 ;$ d.f. $=1$ and high concentration trial: $\chi^{2}=5,5 ; \mathrm{P}=0.02 ;$ d.f. $\left.=1\right)$. No statistical differences were found in the percentage of wasps responding towards the arms of target stimuli between experiments (pinenes, low fungal concentration and high fungal concentration $\left(\chi^{2}=0.2 ; \mathrm{P}=0.9\right.$; d.f. $\left.=2\right)$.

When considering the wasps that made a choice towards the target stimuli (pinenes and fungal volatiles in low and high concentration), the time taken to make a choice was significantly less when the fungal

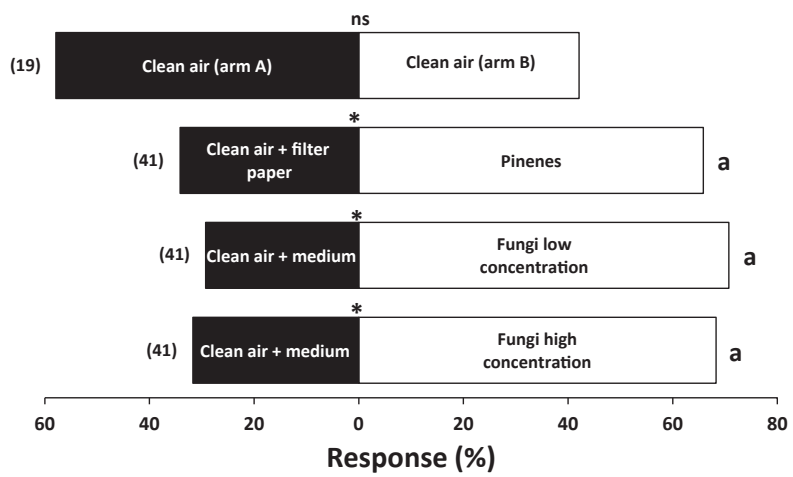

Fig. 2 Percentage of Sirex noctilio females responding towards the different treatments. Four separate experiments were carried out consisting of different odour sources vs. their respective controls. Asterisks denote significant differences at $P<0.05$. Numbers in parentheses indicate the number of wasps responding in each experiment. Same letters at the right side of the bars indicate no significant differences $(P>0.05)$ between experiments in which a choice was observed.

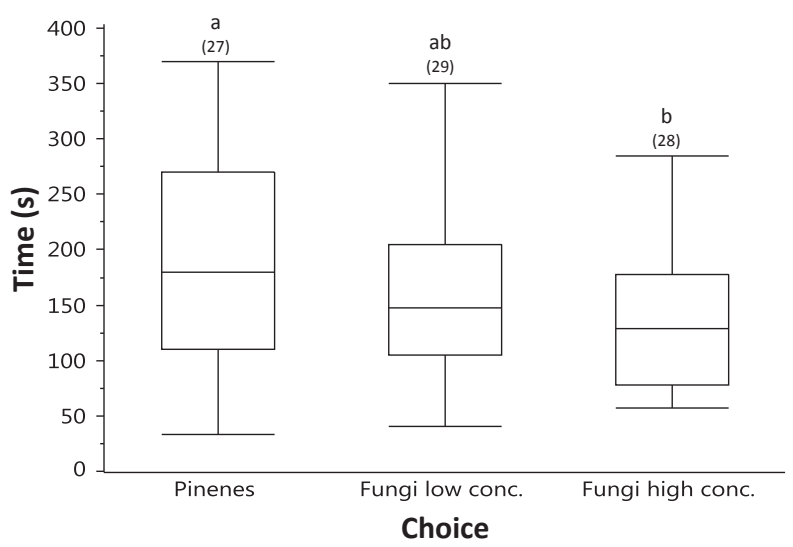

Fig. 3 Time taken to respond towards the arm containing target olfactory stimuli: pinenes, a low concentration of fungal volatiles (fungi low conc.) and a high concentration of fungal volatiles (fungi high conc.). For each box, the top and bottom indicate the interquartile range, and the line across the middle indicates the median value. Error bars indicate the range of the data. Numbers in parentheses indicate the number of wasps biased towards the arm with the stimulus. Different letters above the boxes denote a statistical difference between the experiments $(P<0.05)$.

volatiles were in high concentration compared with the time taken to move towards the arm with the pinenes $(Z=2.14 ; \mathrm{P}=0.032$; fig. 3$)$. No statistical differences were observed between the low vs. high concentration $(Z=1.30 ; \mathrm{P}=0.019)$ or low concentration vs. the pinenes $(Z=0.54 ; \mathrm{P}=0.62)$.

\section{Discussion}

This is the first report to our knowledge to show an attractive response of Sirex noctilio females to Amylostereum areolatum. When presented with fungal volatiles, $S$. noctilo females are not only biased towards the source of the stimulus, but the time taken to make a choice was reduced when the fungal volatiles were in the high concentration compared to the time taken to respond to pinenes. Interestingly, results also indicate that fungal volatiles increase the overall response level (responding wasps vs. non-responding ones). These results suggest that fungal volatiles may elicit an attractive response and moreover, this response could be incremental when compared to tree-derived volatiles. The observed behaviour could be an indication that volatiles present in fungal cultures could be used as a synomone by female wasps to orient towards previously attacked trees.

Present results lead us to hypothesize that $S$. noctilio females could use fungal volatiles to detect previously attacked trees. The wasp attack patterns observed in the field is consistent with this hypothesis. Previous 
research shows that these can be highly aggregated at a stand scale (Corley et al. 2007; Villacide and Corley 2012). The authors of this study conclude that spatial aggregation may contribute to the species population dynamics as wasp outbreaks could be explained by a shift in attack from suppressed trees when wasp population levels are low, to healthy trees when outbreaks begin (see also Aparicio et al. 2013). At this stage, multiple female ovipositions on a single tree are crucial to overcome tree defences (Coutts and Dolezal 1969).

Past work suggests that insects are able to use fungal volatiles as semiochemicals in the process of substrate quality-assessment for oviposition. For instance, Sirex noctilio makes fewer ovipositions in areas previously colonized by Leptographium wingfieldii Morelet, a bark beetle vectored fungi (Ryan et al. 2012). Avoiding such areas may be of considerable reproductive benefit to $S$. noctilio because $L$. wingfieldii outcompetes $A$. areolatum for resources (Ryan et al. 2011). Other works have shown that the parasitoid Ibalia leucospoides Hochenwarth (Hymenoptera: Ibaliidae) can recognize $A$. areolatum volatiles while searching for $S$. noctilo eggs and larva concealed under the wood (Martínez et al. 2006). This supports the fact that fungal volatiles can permeate from infected trees and be used as semiochemicals. More recent studies on the Redbay ambrosia beetle Xyleborus glabratus Eichhoff (Coleoptera: Curculionidae) indicate that a synthetic blend of volatiles based on the odour of its symbiotic fungus improves monitoring lures for this invasive pathogen vector (Kuhns et al. 2014).

Our results could be important contributions to the process of improving baits for monitoring purposes or in control techniques. For instance, by inundating affected areas with fungal volatiles, the probability of aggregated attack to single trees could be reduced. While current monitoring tools used in many invaded regions rely on traps lured with combinations of pine volatiles, these techniques do not offer yet an ideal solution to detect the pest at low densities (Bashford and Madden 2012; Hurley et al. 2014). Future work directed at identifying the behaviourally active chemical compounds emitted by the fungus and possible synergistic effects with tree volatiles will be important at deciphering the chemical ecology of this species.

\section{Acknowledgements}

Funding was provided by the following grants: SAFO-109, UCAR - Ministerio de Agricultura,
Ganadería y Pesca, and PICT- 2011-1775, Agencia Nacional para la Promoción Científica y Tecnológica. We would also like to thank all members of the GEPI lab and Carolina Giese for reading an early version of the manuscript. Bernardo and Estefania Martin from Estancia Mallín Chacay and Nicolas Rodríguez-Argumedo from Estancia Fortin Chacabuco for allowing us to collect wasp-infected trees.

\section{References}

Aparicio JP, Corley JC, Rabinovich JE, 2013. Life history traits of Sirex noctilio f. (Hymenoptera: Siricidae) can explain outbreaks independently of environmental factors. Math Biosci Eng, 10, 1265-1279.

Bashford R, 2008. The development of static trapping systems to monitor for wood-boring insects in forestry plantations. Aust For, 71, 236-241.

Bashford R, Madden JL, 2012. The use of kairomone lures for the detection of Sirex noctilio in susceptible Pinus radiata plantations in Australia. In: The sirex woodwasp and its fungal symbiont. Ed. by Slippers B, de Groot P, Wingfield MJ, Springer, Dordrecht, 159-166.

Bordeaux JM, Dean JFD, 2012. Susceptibility and response of pines to Sirex noctilio. In: The sirex woodwasp and its fungal symbiont. Ed. by Slippers B, De Groot P, Wingfield MJ, Springer, Dordrecht, 31-50.

Böröczky K, Zylstra K, Mccartney N, Mastro V, Tumlinson J, 2012. Volatile profile differences and the associated Sirex noctilio activity in two host tree species in the Northeastern United States. J Chem Ecol, 38, 213-221.

Bruzzone OA, Villacide JM, Bernstein C, Corley JC, 2009. Flight variability in the woodwasp Sirex noctilio (Hymenoptera: Siricidae): an analysis of flight data using wavelets. J Exp Biol, 212, 731-737.

Cooperband M, Böröczky K, Hartness A, Jones T, Zylstra K, Tumlinson J, Mastro VC, 2012. Male-produced pheromone in the european woodwasp, Sirex noctilio. J Chem Ecol, 38, 52-62.

Corley JC, Villacide JM, Bruzzone OA, 2007. Spatial dynamics of a Sirex noctilio woodwasp population within a pine plantation in Patagonia, Argentina. Entomol Exp Appl, 125, 231-236.

Coutts MP, 1969a. The mechanism of pathogenicity of Sirex noctilio on Pinus radiata I. Effects of the symbiotic fungus Amylostereum sp. (Thelophoraceae). Aust J Biol Sci, 22, 915-924.

Coutts MP, 1969b. The mechanism of pathogenicity of Sirex noctilio on Pinus radiata II. Effects of $S$. noctilio mucus. Aust J Biol Sci., 22, 1153-1162.

Coutts MP, Dolezal JE, 1969. Emplacement of fungal spores by the woodwasp, Sirex noctilio, during oviposition. For Sci, 15, 412-416. 
Hurley BP, Garnas J, Cooperband MF, 2014. Assessing trap and lure effectiveness for the monitoring of Sirex noctilio. Agric For Entomol, 17, 64-70.

Kuhns EH, Tribuiani Y, Martini X, Meyer WL, Pe J, 2014. Volatiles from the symbiotic fungus Raffaelea lauricola are synergistic with Manuka lures for increased capture of the Redbay ambrosia beetle Xyleborus glabratus. Agric For Entomol, 16, 87-94.

Madden JL, 1988. Sirex in Australasia. In: Dynamics of forest insect populations: patterns, causes, implications. Ed. by Berryman A, Springer, New York, 407-429.

Madden JL, Coutts MP, 1979. The role of fungi in the biology and ecology of woodwasps (Hymenoptera: Siricidae). In: Insect-Fungus Symbiosis. Ed. by Batra LR, Allanheld, Osmun and Co, Totowa, 165-174.

Martínez AS, Hardie J, 2009. Hygroreception in olfactometer studies. Physiol Entomol, 34, 211-216.

Martínez AS, Fernández-Arhex V, Corley JC, 2006. Chemical information from the fungus Amylostereum areolatum and host-foraging behaviour in the parasitoid Ibalia leucospoides. Physiol Entomol, 31, 336-340.

Martínez AS, Villacide J, Fernández Ajó AA, Martinson SJ, Corley JC, 2014. Sirex noctilio flight behavior: toward improving current monitoring techniques. Entomol Exp Appl, 152, 135-140.

R Development Core Team, 2011. R: A language and environment for statistical computing. R Foundation for Statistical Computing, Vienna.

Ryan K, Moncalvo JM, De Groot P, Smith SM, 2011. Interactions between the fungal symbiont of Sirex noctilio (Hymenoptera: Siricidae) and two bark beetle-vectored fungi. Can Entomol, 143, 224-235.
Ryan K, De Groot P, Smith SM, 2012. Evidence of interaction between Sirex noctilio and other species inhabiting the bole of Pinus. Agric For Entomol, 14, 187-195.

Simpson RF, 1976. Bioassay of pine oil components as attractants for Sirex noctilio (Hymenoptera: Siricidae) using electroantennogram techniques. Entomol Exp Appl, 19, 11-18.

Simpson RF, Mcquilkin RM, 1976. Identification of volatiles from felled Pinus radiata and the electroantennograms they elicit from Sirex noctilio. Entomol Exp Appl, 19, 205-213.

Slippers B, De Groot P, Wingfield MJ, 2011. The Sirex woodwasp and its fungal symbiont. Springer, Dordrecht.

Spradbery JP, 1973. A comparative study of the phytotoxic effects of siricid woodwasps on conifers. Ann Appl Biol, 75, 309-320.

Taylor KL, 1981. The Sirex woodwasp: Ecology and control of an introduced forest insect. In: The ecology of pests: Some Australian case histories. Ed. by Kitching RL, Jones RE, CSIRO, Australia, 231-248.

Thompson BM, Bodart J, Mcewen C, Gruner DS, 2014. Adaptations for symbiont-mediated external digestion in Sirex noctilio (Hymenoptera: Siricidae). Ann Entomol Soc Am, 107, 453-460.

Villacide JM, Corley JC, 2012. Ecology of the woodwasp Sirex noctilio: Tackling the challenge of successful pest management. Int J Pest Manag, 58, 249-256.

Zylstra KE, Dodds KJ, Francese JA, Mastro V, 2010. Sirex noctilio in North America: the effect of stem-injection timing on the attractiveness and suitability of trap trees. Agric For Entomol, 12, 243-250. 